\title{
Disproportionate head growth retardation in cystic fibrosis
}

\author{
S Ghosal, C J Taylor, M Pickering, J McGaw, N Beckles-Willson, J K H Wales
}

\begin{abstract}
Monthly increments of length, weight gain, and head circumference were recorded from birth to 4 years of age in 52 children with cystic fibrosis. At birth the children showed stunting. Standard deviation (SD) scores at birth for height, weight, and head circumference were $-1 \cdot 24,-0.72$, and -1.82 respectively. Over the first four years, length and weight SD scores showed a consistent improvement. However, there was very limited improvement in head circumference, which stabilised 1 SD below the mean from 1.5 years to 4 years. Our data suggest that head growth lags behind gain in height and weight in children with cystic fibrosis despite good nutritional management in early infancy. The data may also support the expression of cystic fibrosis transmembrane conductance regulator in choroid plexus and ependyma. (Arch Dis Child 1995; 72: 150-152)
\end{abstract}

Keywords: head growth, cystic fibrosis, auxology.

Before the mid 1970s, growth failure was considered inevitable in cystic fibrosis. However, by adopting an aggressive nutritional policy, centres such as Toronto have shown that near normal growth can be achieved. ${ }^{12}$ More recently strong links between weight gain and survival have emerged, ${ }^{3}$ and physicians caring for patients with cystic fibrosis now recognise good nutrition as a survival advantage. These improvements in linear growth and weight gain have been achieved by giving high fat, high energy diets and optimising pancreatic supplementation. Recent reports, reflecting the success of such measures, have focused on eventual adult height; there are relatively few data on growth patterns in early childhood. No studies have addressed the long term effects of early undernutrition on head growth in children with cystic fibrosis. We have, therefore, examined prospectively whether improvement in head circumference, weight, and height could be achieved by aggressive nutritional support, and report the results of a longitudinal study of these measurements in children with cystic fibrosis from birth to 4 years of age.

\section{Patients and methods}

Occipitofrontal circumference (OFC), linear height, and weight were measured monthly by a single auxologist using standard anthropometric techniques in 52 children with cystic fibrosis attending the regional centre in Sheffield. Height was measured using a Holtain stadiometer, weight by Weighmaster Babyweigher model $520 / 10$ and Seca alpha model 770 scales, and OFC by using an anthropometric tape. All children had pancreatic insufficiency. The modes of presentation were as follows: 18 with meconium ileus, four through a postnatal screening programme, and the remaining 30 diagnosed on clinical grounds. We confirmed cystic fibrosis by two consecutive abnormal sweat tests. Genotype data were available for 42 children: 30 were $\Delta$ F508 homozygous, the remainder were compound heterozygous for $\Delta \mathrm{F} 508$ and other less common mutations. Our nutritional policy comprised a high energy ( $>120 \%$ dietary reference value) high fat diet, with enough pancreatic enzyme supplements to control steatorrhoea. All patients were reviewed at each visit by a paediatric dietitian and regular dietary assessments were made using a computerised nutrition programme (Dietplan, Forrestfield software). Standard deviation (SD) scores were calculated for height, weight, and head circumference measurements. ${ }^{45}$ Bone age estimations were performed annually using the Tanner and Whitehouse (ii) method. For statistical analysis we used the Student's $t$ test for comparison with population means and the Wilcoxon signed rank test to assess the significance between the age groups.

\section{Results}

Height, weight, and OFC values from birth to 4 years are presented in the table and graphically as mean SD scores in the figure. Mean length, weight, and OFC SD scores were all significantly low at birth compared with the population mean $(-1.24, \mathrm{p}<0.0001,-0.72$, $\mathrm{p}<0.05$; and $-1.82, \mathrm{p}<0.0001$ respectively). The length SD score showed a significant improvement from -1.24 at birth to -0.15 at 4 years $(p<0.001)$. Weight $S D$ score also improved significantly from -1.37 at 6 months to -0.53 at 4 years $(p<0.005)$. In contrast to the gains in height and weight, the OFC SD score reached a plateau of -1 from 1.5 to 4 years and remained significantly low throughout the four years of measurement $(-1 \cdot 05$, $\mathrm{p}<0.0001$ at 4 years).

\section{Discussion}

There are relatively few recent data on growth patterns in patients with cystic fibrosis in childhood. Older reports precede the introduction of high energy diets and more potent pancreatic enzyme supplements. The detailed 
Mean SD scores for height, weight, and OFC in children with cystic fibrosis are given grouped according to age. Values for both sexes were pooled together; values for Student's test are given, based on an expected mean value of zero

\begin{tabular}{|c|c|c|c|c|c|c|c|c|c|}
\hline \multirow{2}{*}{$\begin{array}{l}\text { Age } \\
\text { (years) }\end{array}$} & \multicolumn{3}{|c|}{ Length/height SD score } & \multicolumn{3}{|c|}{ Weight SD score } & \multicolumn{3}{|c|}{ OFC SD score } \\
\hline & No & Mean $(S D)$ & p Value & No & Mean (SD) & p Value & No & Mean $(S D)$ & p Value \\
\hline $\begin{array}{l}\text { Birth } \\
0 \cdot 5 \\
1 \\
1 \cdot 5 \\
2 \\
3 \\
4\end{array}$ & $\begin{array}{l}32 \\
36 \\
44 \\
45 \\
51 \\
48 \\
40\end{array}$ & $\begin{array}{l}-1.24(1.45) \\
-1.03(1.60) \\
-0.80(1.35) \\
-0.62(1.33) \\
-0.29(1.14) \\
-0.17(1.03) \\
-0.15(1.11)\end{array}$ & $\begin{array}{l}<0.0001 \\
<0.0005 \\
<0.0005 \\
<0.005 \\
\text { NS } \\
\text { NS } \\
\text { NS }\end{array}$ & $\begin{array}{l}33 \\
36 \\
45 \\
44 \\
51 \\
48 \\
40\end{array}$ & $\begin{array}{l}-0.72(1.66) \\
-1.37(1.64) \\
-1.36(1.42) \\
-1.12(1.26) \\
-0.84(1.16) \\
-0.70(1.10) \\
-0.53(1.19)\end{array}$ & $\begin{array}{l}<0.05 \\
<0.0001 \\
<0.0001 \\
<0.0001 \\
<0.0001 \\
<0.0001 \\
<0.05\end{array}$ & $\begin{array}{l}32 \\
36 \\
44 \\
45 \\
51 \\
48 \\
40\end{array}$ & $\begin{array}{l}-1.82(1.08) \\
-1.33(1.13) \\
-1.13(1.16) \\
-1.02(1.15) \\
-1.09(1.11) \\
-1.08(1.18) \\
-1.05(1.23)\end{array}$ & $\begin{array}{l}<0.0001 \\
<0.0001 \\
<0.0001 \\
<0.0001 \\
<0.0001 \\
<0.0001 \\
<0.0001\end{array}$ \\
\hline
\end{tabular}

NS = not significant.

measurements of 50 children with cystic fibrosis performed by Sproul and Huang in 1963 serve to illustrate the natural progression of the disease in terms of growth. ${ }^{6}$ After diagnosis and introduction of treatment at 3 months, they recorded initial improvements in growth in both sexes. Median height and weight accelerated from the 3 rd centile to run between the 3 rd and 10 th centiles by 2 years of age. However, from 3.5 years in girls and 6 years in boys, weight gain decreased progressively, falling below the 3rd centile at 6 years in girls and 11 years in boys, with a continuous
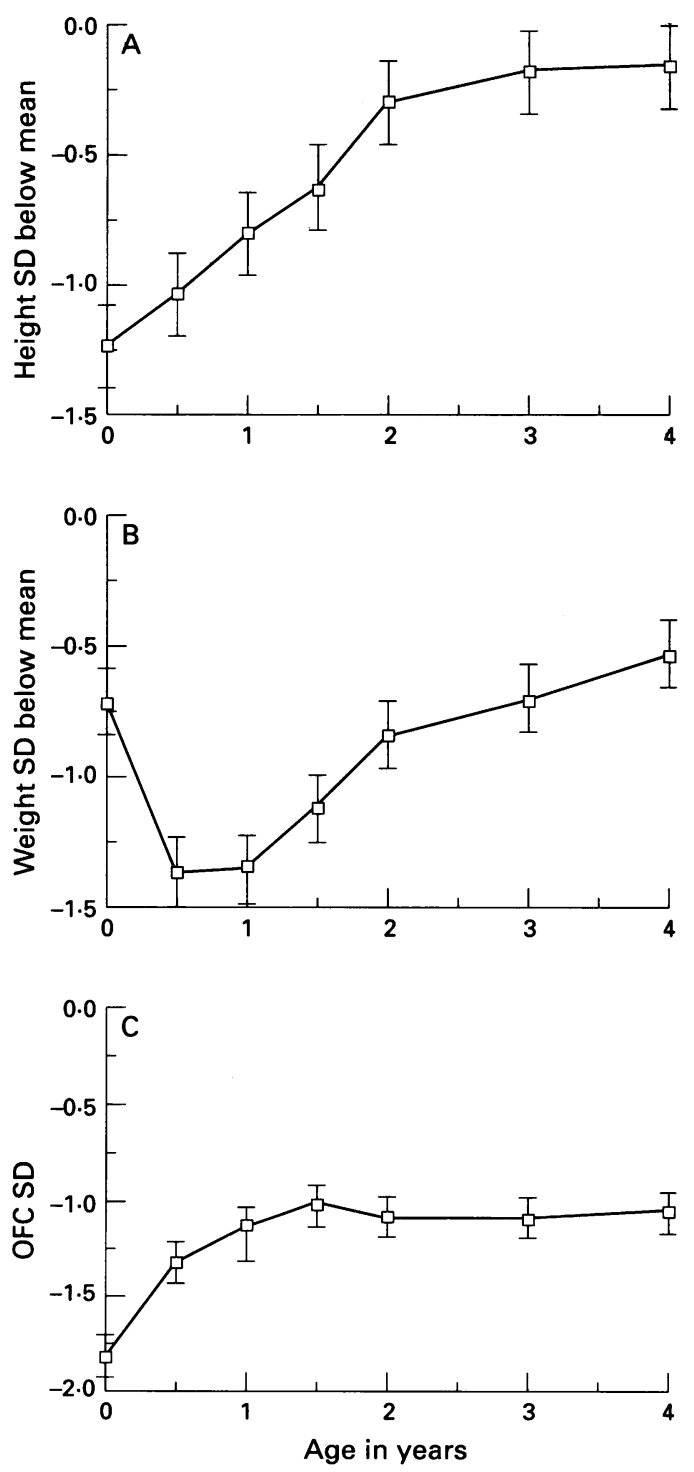

Mean SD scores of change in (A) height, (B) weight, and (C) OFC from birth to 4 years of age; bars show $1 \mathrm{SE}$. decline until 16 years. Linear growth was maintained between the 3rd and 10th centiles until 9-12 years then reached a plateau during early adolescence in both sexes. A further study, in 1975, also demonstrated this relentless decline in weight below the 3 rd centile by 15 years of age. ${ }^{7}$

A more valid comparison is provided by the study of Corey et al on Boston and Toronto patients after the introduction of modern nutritional techniques. ${ }^{2}$ Although this focused on adult height, their demonstration, that growth and weight gain could be maintained between the 31 st and 44 th centiles for both sexes throughout childhood, was encouraging. The progressive improvements in height and weight gain shown by the Sheffield children are similar to those reported in Toronto patients, although the mode of presentation and frequency of pancreatic sufficiency of the Toronto patients limits direct comparison. Linear growth in Swedish children with cystic fibrosis was studied by Karlberg et al. ${ }^{8}$ Their findings were similar; length SD at 3 months was -1.3 below mean improving to -0.19 at 5 years of age.

Unfortunately, there are no comparative data on head growth in children with cystic fibrosis. Lloyd-Still et al included a group of 34 children with cystic fibrosis among a total of 41 malnourished children in a study looking at intellectual development after severe malnutrition in infancy. ${ }^{9}$ Growth parameters were given for 6 and 12 months of age. Head circumference measurements were below the 3rd centile (2 SD below mean), so too were the length and weight. This seems to suggest that head growth is not spared in children with cystic fibrosis and supports our findings. The adverse outcome of the Sheffield children, in terms of head growth, may also reflect early malnutrition. This, in part, may be influenced by the high percentage $(34 \%)$ of Sheffield patients who presented with meconium ileus. The high incidence of meconium ileus in this clinic population is a consequence of centralising neonatal surgery in the Trent region to Sheffield.

It is known that when malnutrition occurs during a significant part of the first year, there may be permanent deficits in head size and linear growth. ${ }^{10}$ In both small for dates and appropriately grown infants, relatively minor undernutrition during a time of very rapid brain growth can result in a deficit in the ultimate size of the brain ${ }^{11}$ and affect brain cell growth and DNA content. ${ }^{12}$ Measurement of 
head circumference appears to be an accurate reflection of the cellular growth of the brain in the first year of postnatal life. ${ }^{12}$ Malnutrition in infancy is also reported to affect intellectual development adversely. ${ }^{9}$ It is also known that intelligence at 4 years correlates directly with head circumference, ${ }^{13}$ although an OFC $<2$ SD below the mean is not incompatible with normal intelligence. ${ }^{14}$ Evidence for catch up in cranial growth is also available. Laron et al reported a marked retardation in growth of the neurocranium in children with isolated growth hormone deficiency. ${ }^{15}$ Treatment with human growth hormone before a chronological age of 5 years or bone age of 3 years resulted in rapid catch up in cranial growth, with normalisation of head size. Malnourished children also demonstrate catch up head growth, after adequate nutritional rehabilitation. ${ }^{16}$

In recent years, postnatal screening has been introduced in Trent, although follow up is too brief for all but the earliest diagnosed patients to be included in this study. The effects of early diagnosis and treatment on head growth will be of interest as little benefit from postnatal screening programmes has been demonstrated except for a reduction in hospital admissions in the first year of life. ${ }^{17}$

This study suggests that, in cystic fibrosis, despite early diagnosis and careful attention to nutrition, head growth lags behind the rest of the body. Intelligence in children with cystic fibrosis appears to be normally distributed, but evidence is limited. ${ }^{18}$ Furthermore, the issue of intellectual performance testing remains controversial. ${ }^{9} 18$ Expression of the cystic fibrosis gene product, the cystic fibrosis transmembrane conductance regulator (CFTR) has also been reported in brain, ${ }^{19} 20$ although its significance is unclear. It is possible that CFTR influences cerebrospinal fluid secretion. This may be deficient in cystic fibrosis, leading to a reduction in brain volume. Studies using magnetic resonance to calculate ventricular volume may throw further light on this matter.
Psychometric testing may also be a useful additional resource for a cystic fibrosis clinic.

Dr S Ghosal is funded by the Cystic Fibrosis Trust.

1 Crozier DN. Cystic fibrosis - a not so fatal disease. Pediatr Clin North Am 1974; 21: 935-50.

2 Corey M, McLaughlin FJ, Williams M, Levison H. A comparison of survival, growth, and pulmonary function in patients with cystic fibrosis in Boston and Toronto. $\mathcal{f}$ Clin Epidemiol 1988; 41: 583-91.

3 Kraemer R, Rudeberg A, Hadorn B, Ross I. Relative underweight in cystic fibrosis and its prognostic value. Acta Paediatr Scand 1978; 67: 33-7.

4 Tanner JM, Whitehouse RH, Takaishi M. Standards from birth to maturity for height, weight, height velocity, and weight velocity: British children, 1965. Part I. Arch Dis Whild 1966; 41: 454-71.

5 Tanner JM, Whitehouse RH, Takaishi M. Standards from birth to maturity for height, weight, height velocity, and weight velocity: British children, 1965. Part II. Arch Dis Child 1966; 41: 613-35.

6 Sproul A, Huang H. Growth patterns in children with cystic fibrosis. F Pediatr 1964; 65: 664-76.

7 Berry HK, Kellog FW, Hung MM, Ingberg RL, Richter L, Gutjahr $C$. Dietary supplement and nutrition in children with cystic fibrosis. Am $\mathcal{F}$ Dis Child 1975; 129: 165-71.

8 Karlberg J, Kjellmer I, Kristiansson B. Linear growth in children with cystic fibrosis. Acta Paediatr Scand 1991; 80: 508-14.

9 Lloyd-Still JD, Hurwitz I, Wolff PH, Shwachman H. Intellectual development after severe malnutrition in infancy. Pediatrics 1974; 54: 306-11.

10 Davies PA, Davis JP. Very low birth-weight and subsequent head growth. Lancet 1970; ii: 1216-9.

11 Graham G. Effect of infantile malnutrition on growth. Federal Proceedings 1967; 26: 139-43.

12 Winick $M$, Rosso P. Head circumference and cellular growth of the brain in normal and marasmic children. $\mathcal{f}$ Pediatr 1969; 74: 774-8.

13 Nelson KB, Deutschberger J. Head size at one year as predictor of four year IQ. Dev Med Child Neurol 1970; 12: 487-95.

14 Pryor HB, Thelander H. Abnormally small head size and intellect in children. $\mathcal{F}$ Pediatr 1968; 73: 593-8.

15 Laron Z, Roitman A, Kauli R. Effect of human growth hormone therapy on head circumference in children with hypopituitarism. Clin Endocrinol (Oxf) 1979; 10: 393-9.

16 Engsner G, Habte D, Siogren I, Vahlquist B. Brain growth in children with kwashiorkor. Acta Paediatr Scand 1974; 63: 687-94.

17 Chatfield S, Owen G, Ryley HC, et al. Neonatal screening of cystic fibrosis in Wales and the West Midlands: clinical assessment after five years of screening. Arch Dis Child 1991; 66: 29-33.

18 Thompson RJ, Gustafson KE, Meghdadpour S, Havrell ES, Johndrow DA, Spock A. The role of biomedical and psychosocial processes in the intellectual and academic functioning of children and adolescents with cystic fibrosis. F Clin Psychol 1992; 48: 3-10.

19 McGrath SA, Basu A, Zeitlin PL. Cystic fibrosis gene and protein expression during fetal lung development. $A m \mathcal{F}$ Respir Cell Mol Biol 1993; 8: 201-8.

20 Hincke MT, Nairn AC, Staines WA. Cystic fibrosis transmembrane conductance regulator is found in brain ventricular epithelium and in choroid plexus. Pediatr Pulmonol 1993; suppl 9: 207. 